\title{
Study on Measurement of the Real Estate Bubble in Guangzhou
}

\author{
Zhipeng Zhong \\ School of Public Administration, Jinan University, Guangzhou, China \\ Email: zzp531837260@163.com
}

How to cite this paper: Zhong, Z. P. (2020). Study on Measurement of the Real Estate Bubble in Guangzhou. Open Journal of Social Sciences, 8, 510-522. https://doi.org/10.4236/jss.2020.84037

Received: March 27, 2020

Accepted: April 21, 2020

Published: April 24, 2020

Copyright $\odot 2020$ by author(s) and Scientific Research Publishing Inc. This work is licensed under the Creative Commons Attribution International License (CC BY 4.0).

http://creativecommons.org/licenses/by/4.0/

\begin{abstract}
With the rapid development of the real estate industry, the real estate bubble has attracted more and more attention. Using the efficacy coefficient method, we measure the real estate bubble of Guangzhou city from 2007 to 2016. The results show that from 2007 to 2016, the comprehensive coefficient of the real estate market bubbles in Guangzhou is on alert and worthy of attention.
\end{abstract}

\section{Keywords}

Real Estate Bubble, Measurement, Worth Warning, Guangzhou

\section{Introduction}

Since the Chinese government promoted the reform of the real estate market, China's real estate market has developed very rapidly. On the one hand, the vigorous development of the real estate market has continuously promoted China's economic growth. On the other hand, economic bubbles have also accumulated, driving the investment boom in the virtual economy. If the virtual economy expands excessively, it will cause a bubble crisis, which will not only affect the healthy development of our national economy and the vital interests of the people, but also affect the safety and security of the financial industry.

The real estate industry is connected with many industries and has high industrial relevance and strong driving force. According to calculations by some developed country scholars, each $1 \%$ increase in the output value of the real estate industry can increase the output value of related industries by $1.5 \%$ to $2 \%$ (Liang, 2007). The real estate industry is accompanied by huge capital and finance, and its rise and fall often bring about great changes in financial assets. From the perspective of risk prevention, countries around the world attach great importance to the stability of the real estate industry, because many world-class 
economic crises are always associated with the collapse of the real estate industry. The real estate industry has made a huge contribution to stimulating economic growth, but the overheating of the economy due to real estate is even more vigilant, which has caused concern about the real estate market bubble. There have been many incidents of bubble economy triggered by the real estate bubble in history.

A bubble is essentially a phenomenon of price movement, a phenomenon in which actual prices severely deviate from the theoretical value, and a real estate bubble refers to the continuous rise in real estate prices caused by factors such as real estate speculation and the market base. Some scholars believe that the real estate bubble is due to real estate developers and buyers having a systemic expectation of future real estate prices, and then adopting speculative behaviors individually, so that real estate prices continue to rise away from the basic value determined by the market foundation. Speculation, expectations, and bounded rationality are still the main reasons for the formation of a real estate bubble (Jiang, 2005). As one of the most developed cities in China, Guangzhou is worthy of attention whether there is a bubble in the real estate market and the extent of the bubble. It is hoped that this research can provide help for our government to effectively control the real estate bubble.

\section{Description of Study Area}

Guangzhou, the capital of Guangdong Province, is located in the central and southern part of Guangdong Province. It is located on the northern edge of the Pearl River Delta and faces the Hong Kong and Macau Special Administrative Regions across the sea. It is known as China's "Southern Gate”. In 2016, Guangzhou's registered population was 8.749 million, of which 1.76 million were rural and 6.94 million were urban. The sex ratio was 100.66, and the population density was 604 people per square kilometer. The total economic output was 1954.7 billion yuan, with a growth rate of $7.9 \%$, of which the tertiary industry accounted for about $69.4 \%$, and the investment in the real estate industry reached 254 billion yuan. The urban per capita disposable income is 50,940 yuan.

\section{Data Sources and Research Methods}

\subsection{Data Sources}

This article collects data from the Guangzhou Statistical Yearbook and Guangdong Statistical Yearbook from 2006 to 2017 according to research needs. Others were obtained from government websites such as the Guangzhou Municipal Bureau of Statistics and the Guangdong Bureau of Statistics.

\subsection{Research Methods}

How to judge whether there is a bubble in China's real estate market and how to measure the degree of the real estate bubble have been the focus of attention in the field of theoretical research and practice. At present, the measurement of real 
estate bubbles in China mainly includes direct test method, indirect test method, index method, and multivariate statistical method. As the real estate basic value data is difficult to obtain, the applicability of the direct inspection method is limited. The indirect test method can only test the presence or absence of bubbles, and cannot measure its size. At the same time, it is difficult to draw valid conclusions even on the issue of measuring whether there is a bubble, due to the accuracy of the data and the span of the time series. The index method and the multivariate statistical method do not require high time span of data, which can avoid the shortcomings of the direct test and indirect test. The simplicity and easy access to data make it the most important method for measuring the real estate bubble. The index method generally selects several evaluation indicators related to real estate development in production, trading, finance, consumption, etc., to compare the actual value of the indicator with the critical value, that is, the allowable value. If it is less than the critical value, there is normally no bubble. The index method can be divided into single index method, multi-index method and efficacy coefficient method. The single index method uses a single evaluation index to measure the existence and size of a real estate bubble by comparing the difference between the actual index value and the threshold value of the index. For example, Lu Jianglin calculated the housing market bubble levels in China's 35 large and medium-sized cities from 2006 to 2008 using the housing price-income ratio as an evaluation index, and concluded that there was a large bubble in general. The multi-indicator method uses a multi-indicator evaluation system that reflects aspects of production, trading, finance, and distribution to measure real estate bubbles, that is, the multi-indicator method. The multi-indicator method generally selects several indicators in the real estate industry such as production, trading, finance, and consumption to form an evaluation index system, and calculates a comprehensive index of indicators by setting thresholds and weights for different indicators. The power coefficient method generally determines a satisfactory value and an unallowable value for each evaluation index. The satisfactory value is the upper limit and the unallowable value is the lower limit. The degree to which each index achieves a satisfactory value is calculated, and the score of each index is determined by this. Then the weighted average is used for synthesis to evaluate the comprehensive status of the research object.

Based on the current research status at home and abroad, this paper selects suitable measurement indicators for the real estate bubble. This article adopts the efficacy coefficient method to measure the real estate bubble in Guangzhou by comparing the difference between the actual index value and the threshold value of the index.

According to the principle of multi-objective programming, the efficacy coefficient method determines a satisfactory value and an unallowable value for each evaluation index, with the satisfactory value as the upper limit and the unallowable value as the lower limit. It calculates the degree to which each index achieves a satisfactory value, and uses this to determine the score of each index, and then 
integrates them through a weighted average to evaluate the comprehensive status of the subject. The specific steps are:

1) Determine early warning indicators by collecting data values from 2007 to 2016 for which early warning indicators can be obtained, and calculate actual observation values $X_{i}$.

2) Determine the satisfactory value $X_{i}^{r}$ and the impermissible value $X_{i}^{s}$ of each indicator based on historical statistical data and international experience.

3) Use the formula to calculate the efficacy coefficient of each indicator. The calculation formula is as follows:

$$
\delta_{i}=\frac{X_{i}-X_{i}^{s}}{X_{i}^{r}-X_{i}^{s}} \times 40+60
$$

4) The weighting calculation is performed according to the calculated efficacy coefficient and the weight given to the measurement index to obtain the comprehensive early warning coefficient $K$ of the real estate bubble in the place. The calculation formula is as follows:

$$
K=\sum \delta_{i} w_{j}
$$

5) Use the comprehensive warning coefficient $K$ to judge the degree of speculative bubbles. Drawing on the research results of Weizhe $\mathrm{Li}$ and Qu Bo in 2002, the early warning levels are divided into 4 levels, and the early warning interval is divided as shown in Table 1 .

\section{Select Evaluation Indicators}

\subsection{Real Estate Investment Indicators}

The current investment status of real estate reflects whether the real estate investment is overheating and how the pressure on the real estate bubble will be a warning in advance, so the indicators of real estate investment status can to some extent alert the extent of the real estate bubble.

1) Amount of real estate investment/Social total fixed assets investment

The ratio of real estate investment to total fixed asset investment in the whole society reflects the current market's enthusiasm for real estate investment. This indicator can effectively reflect the rationality of real estate investment in social fixed asset investment. The ratio is too large, indicating that companies are keen to invest in real estate, and a large amount of funds in the society has flowed into the real estate industry, which has led to the overheating of the real estate industry, which reflects the existence of a real estate bubble to a certain extent. The internationally recognized alert level for the proportion of real estate development investment in fixed assets investment in the whole society is $10 \%$ (Wang \&

\begin{tabular}{|c|c|c|c|c|}
\hline $\mathrm{K}$ & $>60$ & $60-0$ & $0--100$ & $<-100$ \\
\hline Warning level & SAFE & Worth warning & dangerous & Highly dangerous \\
\hline
\end{tabular}

Table 1. Comprehensive measurement coefficient safety level. 
Liang, 2015). In fact, as early as 2004, China's real estate investment accounted for $18.78 \%$ of the total fixed asset investment in the society, far exceeding International standards. Therefore, based on the actual development of China and recent research by scholars, the satisfaction value of this indicator is set to $20 \%$, and the allowable value is $30 \%$.

2) Real estate investment/GDP

The proportion of real estate investment in GDP reflects the dependence of the national economy on the real estate industry. The real estate industry is an important sector in the entire national economy. Its level of development should be coordinated with the overall level of social and economic development. The amount of real estate investment in total GDP The excessively large proportion indicates that the entire national economic development structure is unhealthy, and the driving force for economic growth is too dependent on the real estate industry. Once the collapse of the real estate industry occurs, the entire national economy will also be fatally hit. The proportion of China's real estate development investment in GDP has reached the 5\% warning line since 1999, and has since climbed all the way, reaching $9.6 \%$ in 2004 . Therefore, based on China's development status and national conditions, the satisfaction value of this indicator is set to $5 \%$, and the allowable value is $10 \%$.

\subsection{Real Estate Transaction Indicators}

1) Commercial housing construction area/completion area

The ratio of the construction area and the completed area of commercial buildings can reflect the supply of the real estate market in the future, and thus reflect the real estate market bubble. The construction area of commercial housing reflects the supply of existing housing in the next one to two years, and the completed area of commercial housing is the performance of real estate investment lagging by one to two years. When the indicator value is large, it means that the real estate supply is too large, which means that the real estate bubble will be larger. Therefore, the satisfaction value of this indicator is set to 3 , and the allowed value is 4 .

2) Real estate investment/GDP

Completion area/sale area of commercial buildings

The ratio of the completed area of commercial housing to the sales area of commercial housing can reflect the supply and demand situation of the real estate market in a certain period. The completed area of commercial housing is a measure of supply in the real estate market, and the sold area of commercial housing is a measure of demand in the real estate market. The ratio of the two can tell the heat and prosperity of the real estate market during this period. This indicator is too large, indicating that the real demand in the real estate market is not as large as the market shows, that is, the larger the real estate bubble. Internationally, this indicator is usually set to $1.0-1.2$, so the satisfaction value of this indicator is set to 1 , and the allowed value is 1.2. 


\subsection{Real Estate Price Indicators}

This article selects seven indicators. The satisfaction value and allowable value of each indicator are shown in Table 2, and the observed value of each indicator is shown in Table 3.

1) Price-to-income ratio

The price-to-income ratio is designed based on excessive speculative demand in the causes of the real estate bubble, reflecting the relative purchasing power of residents and the affordability of households for the current year. The smaller the ratio, it means that the residents have a strong ability to consume housing. It also shows that the price of real estate is affordable by the income of the residents, and that the development of the real estate market is healthy. The higher the ratio, the lower the ability of residents to pay.

Table 2. Satisfactory and allowable values of indicators.

\begin{tabular}{|c|c|c|c|c|c|}
\hline \multirow{2}{*}{ Serial number } & \multirow{2}{*}{ Criterion layer } & \multirow{2}{*}{ Indicator layer } & \multirow{2}{*}{ Satisfaction } & \multicolumn{2}{|c|}{ Bubble standards } \\
\hline & & & & Slight & Not allowed value \\
\hline 1 & $\begin{array}{l}\text { Real estate } \\
\text { investment }\end{array}$ & $\begin{array}{l}\text { Real estate investment/social fixed assets investment } \\
\text { B1 }\end{array}$ & 0.2 & $0.2-0.3$ & 0.3 \\
\hline 2 & $\begin{array}{l}\text { indicators } \\
\quad \mathrm{A} 1\end{array}$ & $\begin{array}{c}\text { Real estate investment/GDP } \\
\text { B2 }\end{array}$ & 0.05 & $0.05-0.1$ & 0.1 \\
\hline 3 & $\begin{array}{l}\text { Real estate } \\
\text { transaction }\end{array}$ & $\begin{array}{l}\text { Commercial housing construction area/completion area } \\
\qquad \text { B3 }\end{array}$ & 3 & $3-4$ & 4 \\
\hline 4 & $\begin{array}{l}\text { indicators } \\
\quad \mathrm{A} 2\end{array}$ & $\begin{array}{l}\text { Completion area/sale area } \\
\text { B4 }\end{array}$ & 1 & $1-1.2$ & 1.2 \\
\hline 5 & & $\begin{array}{l}\text { Price-to-income ratio } \\
\text { B5 }\end{array}$ & 6 & $6-8$ & 8 \\
\hline 6 & $\begin{array}{l}\text { Real estate price } \\
\text { indicators } \\
\text { A3 }\end{array}$ & $\begin{array}{l}\text { House price growth rate/GDP growth rate } \\
\text { B6 }\end{array}$ & 1 & $1-2$ & 2 \\
\hline 7 & & $\begin{array}{l}\text { House price index growth rate/CPI growth rate } \\
\qquad \text { B7 }\end{array}$ & 1 & $1-2$ & 2 \\
\hline
\end{tabular}

Table 3. Observed values of various indicators.

\begin{tabular}{cccccccc}
\hline year & B1 & B2 & B3 & B4 & B5 & B6 & B7 \\
\hline 2007 & 0.378 & 0.099 & 5.124 & 0.605 & 6.432 & 0.685 & 1.082 \\
2008 & 0.363 & 0.092 & 4.887 & 0.858 & 6.883 & 1.084 & 1.109 \\
2009 & 0.307 & 0.089 & 5.147 & 0.784 & 5.439 & -1.535 & 0.864 \\
2010 & 0.301 & 0.092 & 5.906 & 0.779 & 7.887 & 3.298 & 1.532 \\
2011 & 0.383 & 0.025 & 5.951 & 1.082 & 8.327 & 1.022 & 1.099 \\
2012 & 0.365 & 0.027 & 6.078 & 0.968 & 10.079 & 3.345 & 1.266 \\
2013 & 0.353 & 0.037 & 7.149 & 0.671 & 8.363 & -0.655 & 0.883 \\
2014 & 0.371 & 0.049 & 4.882 & 1.246 & 8.598 & 1.169 & 1.067 \\
2015 & 0.395 & 0.118 & 6.183 & 0.914 & 9.297 & 0.866 & 1.054 \\
2016 & 0.445 & 0.130 & 8.369 & 0.617 & 8.736 & 0.120 & 0.983 \\
\hline
\end{tabular}


Some scholars believe that the price-to-income ratio is a good indicator of the bubble level in the urban residential market. The reason is that the price-to-income ratio is an index selected according to the causes of the real estate bubble and the actual value of the price-to-income ratio is easy to obtain (Wang \& Liang, 2015). Internationally, the reasonable range of house price income ratio is generally between $3-6$. However, according to the actual situation in China, the house price income ratio in most years since 1998 has been above 6 (Wu \& Yu, 2007). Some scholars believe that there is a bubble in China's real estate market. However, due to many factors such as the level of national economic development and the actual needs of residents, this international experience data is not applicable to China. According to China's national conditions, the satisfaction value of this indicator is set to 6 and the allowed value is set to 8 . The calculation method adopted: the per capita housing area in the city is multiplied by the sales price per unit of commercial housing, which is then compared with the per capita disposable income of urban residents.

2) House price growth rate/GDP growth rate

The real estate price growth rate is compared with the economic growth rate to reflect the degree of deviation between the virtual economy and the real economy (Jiang, 2009). The growth rate of real estate prices reflects the trend of housing prices over a certain period of time. If the growth rate of housing prices is much larger than the growth rate of GDP, it indicates that the growth rate of housing prices is too fast and exceeds the development rate of the real economy. The ratio of the two can measure the dynamic change of the growth rate of real estate relative to the real economy, and monitor the trend of real estate economic bubble. Therefore, the index satisfaction value is set to 1 and the non-permissible value is set to 2 .

3) House price index growth rate/CPI growth rate

The ratio of the growth rate of the house price index to the growth rate of the CPI reflects the attitude of residents to the real estate market. Real estate is used as an asset to maintain the purchasing power of money. The growth rate of the house price index should theoretically be synchronized with the change in the growth rate of the CPI. Exceeding the level of payment that residents can afford reflects the existence of a real estate bubble. Therefore, the satisfaction value of this indicator is set to 1 , and the non-permissible value is set to 2 .

\section{Determination of Indicator Weights}

This article integrates the subjective and objective and objective weighting methods, and adopts the objective entropy weight method and subjective analytic hierarchy process to weight the measurement indicators.

\subsection{Entropy Method}

The entropy weight method is an objective method to determine the weight. Entropy is a measure of the degree of disorder of the system, and information is a 
measure of the degree of order of the system. The smaller the information entropy of the indicator, the greater the amount of information and the more weight high.

1) Dimensional Normalization

First, we perform dimensional normalization on the evaluation indicators. Assume that there is a raw data matrix: $A=\left(a_{i j}\right) m \times n$, which consists of $\mathrm{m}$ evaluation indicators and $\mathrm{n}$ evaluation object. After normalizing it, we get: $R=\left(r_{i j}\right) m \times n$.

For bigger and better benefit indicators:

$$
r_{i j}=\frac{a_{i j}-\min \left\{a_{i j}\right\}}{\max \left\{a_{i j}\right\}-\min \left\{a_{i j}\right\}}
$$

For smaller and better cost indicators:

$$
r_{i j}=\frac{\max \left\{a_{i j}\right\}-a_{i j}}{\max \left\{a_{i j}\right\}-\min \left\{a_{i j}\right\}}
$$

2) Defining Entropy

In a system with $\mathrm{m}$ indicators and $\mathrm{n}$ evaluation objects, the entropy $H_{j}$ of the $\mathrm{i}$-th indicator can be calculated as follows:

$$
H_{j}=-k \cdot \sum_{i=1}^{n} f_{i j} \cdot \ln f_{i j} \quad j=1,2, \cdots, m
$$

$f_{i j}=\frac{r_{i j}}{\sum_{1}^{n} r_{i j}}, k=\frac{1}{\ln n}$, assume that when $f_{i j}=0, f_{i j} \cdot \ln f_{i j}=0$.

3) Defining Entropy Weight

The entropy weight $W_{j}$ is calculated as follows:

$$
W_{j}=\frac{1-h_{j}}{m-\sum_{i-1}^{m} h_{j}}\left(0 \ll W_{j} \ll 1, \sum_{1}^{n} w_{j}=1\right)
$$

The weight of each indicator calculated by the entropy weight method is as shown in Table 4.

\subsection{Analytic Hierarchy Process}

The analytic hierarchy process, or AHP for short, was formally proposed by the American operations researcher Thomas Setty in the mid1970s (Guo, Zhang, \& Sun, 2007). Analytic Hierarchy Process (AHP) is suitable for situations where there is uncertainty and subjective information, and analysis is performed in a logical way using experience, insight and intuition.

The analytic hierarchy process includes the following steps: 1) establishing a hierarchical structure model; 2) constructing a pair comparison matrix; 3)

Table 4. Weights of each indicator.

\begin{tabular}{cccccccc}
\hline indicator & B1 & B2 & B3 & B4 & B5 & B6 & B7 \\
\hline Weights & 0.11858 & 0.194892 & 0.105309 & 0.125792 & 0.1700 & 0.1871 & 0.0984 \\
\hline
\end{tabular}


calculating a weight vector and performing consistency check; 4) calculating a combination weight vector and performing combination consistency test.

\subsection{Calculation of Combination Weights}

Assuming that the weight determined by the analytic hierarchy process (AHP) is $w_{j}^{\prime}$ and the weight determined by the entropy weight method is $w_{j}^{\prime \prime}$, the combined weight $w_{j}$ of the two methods in Table 5 and Table 6:

$$
w_{j}=\frac{w_{j}^{\prime \prime} w_{j}^{\prime}}{\sum_{i=1}^{m} w_{j}^{\prime \prime} w_{j}^{\prime}}
$$

\section{Results and Analysis}

The measurement results are shown in Table 6 and Table 7. From 2007 to 2016, Guangzhou's economy developed rapidly. The total GDP has increased from 714.03 billion yuan to 19.9544 billion yuan, an increase of $173.7 \%$ in 10 years. Although the GDP growth rate has been reduced in recent years, it has maintained a growth rate of about $8 \%$. In 2007, the per capita disposable income of

Table 5. Combination weight of each indicator.

\begin{tabular}{cccccccc}
\hline indicator & B1 & B2 & B3 & B4 & B5 & B6 & B7 \\
\hline Combined weight & 0.1824 & 0.0999 & 0.0793 & 0.0474 & 0.4443 & 0.0800 & 0.0667 \\
\hline
\end{tabular}

Table 6. Observed values of various indicators.

\begin{tabular}{cccccccc}
\hline year & B1 & B2 & B3 & B4 & B5 & B6 & B7 \\
\hline 2007 & 28.92 & 61.15 & 15.03 & 178.92 & 91.36 & 112.59 & 96.70 \\
2008 & 34.97 & 66.31 & 24.54 & 128.39 & 82.33 & 96.64 & 95.65 \\
2009 & 57.08 & 68.45 & 14.13 & 143.14 & 111.23 & 201.41 & 105.44 \\
2010 & 59.44 & 66.79 & -16.22 & 144.20 & 62.26 & 8.09 & 78.72 \\
2011 & 26.98 & 120.34 & -18.03 & 83.52 & 53.47 & 99.11 & 96.04 \\
2012 & 34.14 & 118.13 & -23.13 & 106.35 & 18.41 & 6.21 & 89.37 \\
2013 & 38.80 & 110.45 & -65.97 & 165.73 & 52.73 & 166.19 & 104.68 \\
2014 & 31.42 & 100.92 & 24.74 & 50.72 & 48.03 & 93.22 & 97.33 \\
2015 & 21.83 & 45.52 & -27.32 & 117.13 & 34.07 & 105.37 & 97.83 \\
2016 & 1.81 & 36.01 & -114.77 & 176.64 & 45.28 & 135.21 & 100.68 \\
\hline
\end{tabular}

Table 7. Comprehensive measurement indexes by year 2007-2016.

\begin{tabular}{ccccccccc}
\hline year & $K$ & level & year & $K$ & level & year & $K$ & level \\
\hline 2007 & 77.10 & safe & 2011 & 57.56 & warning & 2014 & 55.47 & warning \\
2008 & 71.72 & safe & 2012 & 35.87 & warning & 2015 & 42.00 & warning \\
2009 & 97.71 & safe & 2013 & 64.43 & safe & 2016 & 40.83 & warning \\
2010 & 56.62 & warning & & & & & & \\
\hline
\end{tabular}


urban residents 22,469.2 yuan. In 2016, the figure was 50,940.7 yuan, an increase of $126.7 \%$, and the living standards of the people have greatly improved. At the same time, the development of Guangzhou's real estate market can also be described as fiery. From the basic data, the real estate investment in 2007 was 70.38 billion yuan. By 2012, the real estate investment has risen to 254.08 billion yuan, an increase of $261 \%$ in 10 years. The construction area of commercial buildings increased from 35.944 million square meters in 2007 to 10.061 million square meters in 2016, an increase of $180 \%$. The completed area of commercial buildings increased from 7.014 million square meters in 2007 to 12.022 million square meters in 2016, an increase of $71.5 \%$. The floor space of commercial buildings increased from 11.586 million square meters in 2007 to 19.491 million square meters in 2016, an increase of $68 \%$.

Comparing the overall economic development data of Guangzhou with the real estate industry development data, it is not difficult to see that the overall development momentum of the real estate industry far exceeds the overall economic development momentum, which can also prove the importance of the real estate industry as a leading industry that drives the development of the national economy. In addition, the real estate development momentum is rapid. The real estate investment volume has maintained a high increase almost every year, and a large amount of capital has been invested in the real estate industry. Comparing the increase in the construction area of commercial housing, the completed area of commercial housing and the sales area of commercial housing, we can make a preliminary judgment on the real estate industry. There may be overheating.

\subsection{Analysis of Single Indicators}

1) Investment in real estate/Investment in fixed assets

The lowest value of this indicator is 0.301 in 2010 and the highest value is 0.445 in 2016. The observed value of the indicator from 2007 to 1016 shows a wave dynamic trend, but even the lowest in 2010 is higher than the allowed value of this indicator. This value far exceeds the international warning line of 0.1. From a single indicator, there is a severe real estate bubble in Guangzhou.

2) Real estate investment/GDP

The lowest value of this indicator is 0.089 in 2009 and the highest value is 0.130 in 2016 . The indicator shows an overall upward trend and the fluctuation range is small. The permissible value of this indicator is 0.1 , which did not exceed the permissible value from 2007 to 2010, and it is considered that there is a slight foam; but since 2011, it has exceeded the permissible value, and is considered to be a serious foam.

3) Construction Area/Completed Area of Commercial Buildings

The lowest value of this indicator is 4.882 in 2014, and the highest value is 8.369 in 2016, showing an overall upward trend in volatility. The observed values from 2007 to 2016 all exceeded the permissible value 4, and 8.369 in 2016 more 
than doubled the permissible value. The degree of foam reflected from this indicator was extremely serious.

4) Completion Area/Sales Area of Commercial Buildings

The lowest value of this indicator was 0.615 in 2007 and the highest value was 1.246 in 2014 . The setting of this indicator is not allowed to be 1.2 , and the satisfactory value is 1 . Only the observations in 2014 from 2007 to 2016 exceeded the allowable values, and it can be considered that there is a serious bubble; the observations in 2010 are in the range of 1 - 1.2. Within the range, a slight foam can be considered.

5) Price to income ratio

The lowest value of this indicator was 5.439 in 2009, and the highest value was 10.079 in 2012. It showed an upward trend from 2007 to 2012, reached the highest point in 2012, and then showed a volatile trend. The allowable value of this indicator is 8 and the satisfaction value is 6 . The observed values in 2007 and 2008 are in the range of $6-8$, and it can be considered that there is a slight foam; the observed values in 2009 are less than 6 , and there can be considered no foam; the rest Years exceeded the permissible value of 8 and considered a severe bubble.

6) House price growth rate/GDP growth rate

The lowest value of this indicator is -1.535 in 2009 and the highest value is 3.345 in 2012. The overall fluctuation is large. The allowable value of this indicator is 2 and the satisfactory value is 1 . Among them, the observations in 2007, 2009, 2013, 2015, and 2016 are all less than 1, and it can be considered that there is no bubble; in 2008, 2011, and 2014, the observations are in the range of $1-2$, and it can be considered to be slightly Foam; observations in 2012 were greater than 2 and severe foam was considered to be present.

7) House price index growth rate/CPI growth rate

The lowest value of this indicator was 0.864 in 2009, and the highest value was 1.532 in 2010, showing an overall fluctuation trend. The allowable value of this indicator is 2 and the satisfactory value is 1 . The observed values from 2007 to 2016 are below the allowable value, and there is no serious bubble. However, except for 2009, 2013, and 2016, the observed values in the other years are in the range of $1-2$, and there is a slight foam.

\subsection{Foam Index Analysis}

From the measurement results, from 2007 to 2016, the measured value $\mathrm{K}$ of the foam degree was higher than 60 in four years, which were 2007, 2008, 2009, and 2013 , and the remaining six years were in the range of 60 - 100. According to the judgment criteria of the bubble early-warning evaluation system, the $K$ value was in a safe range in 2007, 2008, 2009, and 2013, and the real estate market was developing steadily. From 2010 to 2012, from 2014 to 2016, the $K$ value was in a warning range, the real estate market was in a state of warning, and the real estate market was overheated or even foaming. From 2007 to 2009, the real estate 
market was in a safe state. In 2009, the $K$ value was 97.71 , the highest value in these 10 years. Compared with 2008, the value of $K$ has increased to some extent in 2009. The reason behind the analysis may lie in the global financial crisis in 2008, the overall economic downturn in the country, and the real estate industry is unavoidable, and the heat has declined. It is not difficult to see from the specific indicators. Except for the construction area/completion area of commercial buildings in 2009, other individual indicators are lower than in 2008. After 2009, the real estate market was hot again, and real estate investment increased sharply. 2010 was a year when real estate prices in Guangzhou rose sharply. The growth rate of house prices/GDP and house price index/CPI rose to their highest levels in 10 years. The value of $\mathrm{K}$ dropped sharply from the safety value of 97.71 in 2009 to the alert value of 56.62, breaking through the safe and stable area for the development of the real estate market. After 2009, a series of national economic stimulus strategies and the implementation of various preferential policies have greatly stimulated economic development. The real estate industry has a strong attractiveness to funds. In addition, Guangzhou has a huge market potential as a first-tier city. A large amount of investment funds came, the market showed a rapid development trend, the "property market fever" appeared, the bubbles of high housing prices gradually increased, and the real estate market entered a state of alert. From 2010 to 2012, the real estate market continued to be hot and the rapid development of the real estate industry caused a sharp rise in the bubble level. The real estate bubble index in Guangzhou exceeded the crisis warning line for three consecutive years. The $K$ value fell by 35.87 in 2012, the lowest value in 10 years. The bubble in Guangzhou's real estate market reached a high value under continuous accumulation. The property market was obviously overheated. Speculative property speculation was increasing, and market prices deviated from actual value there is a certain crisis. The situation has improved slightly after 2012, the bubble index has picked up in 2013, and the measured value of 64.43 is back to the safe line again. After the crazy property market fever in 2012, a series of regulatory policies were involved, and people's attitudes towards real estate returned to rationality. The real estate fever was curbed to a certain extent, housing prices fell to a certain extent, and the real estate bubble was reduced. However, after 2013, the $K$ value continued to decline for three consecutive years from 2014 to 2016, and remained under the alert line for three consecutive years. After only one year of cooling down, the real estate market has heated up again, and the real estate investment has increased from 1572 in 2013. The yuan has risen to 254 billion yuan in 2016, a huge increase, and the real estate industry has entered a state of alert.

\section{Conclusion}

1) During the 10 years from 2007 to 2016, the comprehensive measurement coefficient $\mathrm{K}$ of the six real estate bubbles in Guangzhou was less than 60, showing a state of alert, from 2010 to 2012 and 2014 to 2016, respectively. The 
four-time foam comprehensive measurement coefficient $K$ is greater than 60 , which is from 2007 to 2009 and 2013.

2) In addition to the bubble's comprehensive measurement coefficient rising to a safe value of more than 60 in 2013, Guangzhou's real estate market continues to face foaming risks after 2009, of which Guangzhou's real estate bubble was the worst in 2012.

3) As a whole, Guangzhou's real estate market is on alert, the market is facing the risk of foaming, and there is a possibility of further increase, and precautions are needed.

4) Facing the possible bubble risk, the government should control the unreasonable rise in commodity housing prices by adjusting the supply of land resources. In addition, the government should improve the land management system and strengthen the supervision of real estate developers.

\section{Conflicts of Interest}

The author declares no conflicts of interest regarding the publication of this paper.

\section{References}

Guo, J. Y., Zhang, B., \& Sun, Q. Y. (2007). Research and Application of Analytic Hierarchy Process. Chinese Journal of Safety Science, No. 5, 148-153.

Jiang, C. H. (2005). Empirical Analysis of Speculative Bubbles in China's Real Estate Market, Management World, No. 12, 71-84+171-172.

Jiang, N. P. (2009). Analysis and Establishment of Measurement Indicators of China's Real Estate Bubble. Contemporary Finance and Economics, No. 10, 91-98.

Liang, Y. F. (2007). Empirical Analysis of the Coordinated Development of the Real Estate Market and the National Economy. Chinese Social Science, No. 3, 74-84.

Wang, H., \& Liang, M. P. (2015). Two Main Measurement Methods of the Current Real Estate Bubble in China: Research Ideas, Misunderstandings and Applicability Analysis. Macroeconomic Research, No. 2, 78-85.

Wu, D. B., \& Yu, X. Y. (2007). The Real Estate Bubble and Empirical Analysis. Economic Research Guide, No. 2, 187-189. 